\title{
COMPRENSIÓN TEXTUAL, CONOCIMIENTO Y CULTURA ESCRITA: RESULTADOS DE UNA INVESTIGACIÓN CON ESTUDIANTES DE LA UNIVERSIDAD DEL VALLE.
}

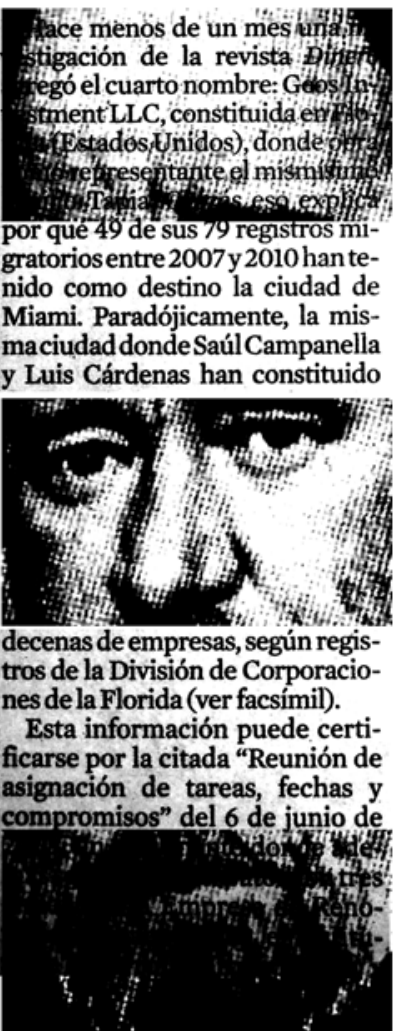

Face menos de un meshura Stigación de la revista Ditien 'egó el cuarto nombre: $\mathrm{G}$ e el cuarto nombre stment LLC, constituida ew Fistados Únidos), dondé ont ing

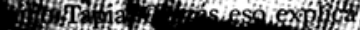
por que 49 de sus 79 registros migratorios entre 2007 y 2010 han tenido como destino la ciudad de Miami. Paradójicamente, la mismaciudaddondeSaúl Campanella y Luis Cárdenas han constituido

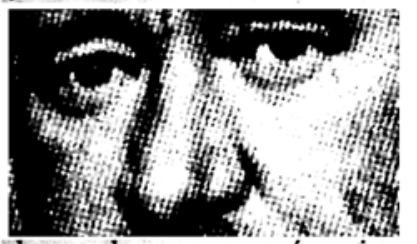

decenas de empresas, según registros de la División de Corporaciones de la Florida (ver facsímil).

Esta información puede certificarse por la citada "Reunión de asignación de tareas, fechas y compromisos" del 6 de junio de
Por:

\author{
Alejandro Ulloa Sanmiguel \\ Profesor Titular \\ Escuela de Comunicación Social \\ Facultad de Artes Integradas \\ Universidad del Valle \\ ausa52@hotmail.com
}

\author{
Giovanna Carvajal Barrios \\ Profesora asociada \\ Escuela de Comunicación Social \\ Facultad de Artes Integradas \\ Universidad del Valle \\ giovanacarv@hotmail.com
}

\section{RESUMEN}

El artículo analiza los resultados de la prueba de lectura diseñada y aplicada al interior de una investigación sobre la cultura escrita, tecnocultura y conocimiento en la Universidad del Valle. Dicha prueba hizo énfasis en la capacidad de los estudiantes para hacer diferentes tipos de inferencias, así como indaga por los conocimientos procedimentales requeridos para realizar una lectura de doble vía (ascendente y descendente), reconociendo las marcas del texto, sus relaciones intertextuales, la presencia de distintos enunciadores y la elaboración implícita de la macroestructura del texto leído, como parte del proceso de comprensión. El artículo presenta una caracterización de la prueba y construye hipótesis -con base en el modelo teórico propuesto desde la lingüística textual y la teoría de la enunciación- sobre la manera como los estudiantes llegaron a resolver cada una de las preguntas del cuestionario (qué debieron hacer para responderla correctamente y cómo se explica que hayan errado); así mismo evalúa su capacidad de leer desde la perspectiva de la organización del texto, como una manifestación de su grado de adscripción a la cultura escrita.

\section{Palabras claves:}

cultura escrita, conocimiento procedimental, comprensión textual, lectura en doble vía. 
Este artículo presenta los resultados parciales del proyecto de investigación "Los estudiantes de la Universidad del Valle: su relación con la cultura escrita y la tecnocultura contemporánea”, realizada entre los años 2007 y 2008.

En una primera investigación (2003-2004), apoyados en herramientas estadísticas, aplicamos una prueba de lectura y una prueba de escritura a 260 estudiantes de la Universidad del Valle, para diagnosticar su desempeño en la producción y comprensión de textos expositivo-argumentativos en el momento en que cursaban su segundo semestre de carrera. Así mismo, a través de la aplicación de una encuesta, conocimos sus relaciones con la cultura escrita y con la tenocultura contemporánea (medios de comunicación y nuevas tecnologías) durante sus estudios de educación básica, media y en el corto tiempo que llevaban en la universidad. A partir de los resultados de las pruebas y de los datos derivados de la encuesta (cruces de variables), planteamos algunas relaciones entre sus modos de relacionarse con la cultura escrita y con la tecnocultura y la incidencia de ello en las formas de apropiación de conocimientos en el ámbito universitario (Ulloa y Carvajal, 2004, 2005, 2009).

La segunda investigación, cuyos resultados estamos presentando, surgió precisamente de los hallazgos de la primera, algunos de los cuales se plantearon como interrogantes y nuevas hipótesis que tendrían que ser abordados en futuros estudios. Nos preguntábamos, por ejemplo, de qué manera su permanencia en la universidad ha incidido en las relaciones de los estudiantes con la cultura escrita y con la tecnocultura contemporánea, y en qué forma dicha relación ha afectado -positiva o negativamente- el proceso de formación académica, teniendo en cuenta que desde la perspectiva de esta investigación, tanto la cultura escrita como la tecnocultura contemporánea constituyen mediaciones cognitivas fundamentales en la vida universitaria (Ulloa y Carvajal 2006). Para abordar estos interrogantes, seleccionamos un grupo de 20 estudiantes que participaron en el primer proyecto -según una caracterización derivada del marco teórico de la investigación- a quienes se les aplicaron una nuevas pruebas de lectura y escritura, con características semejantes a las de la primera investigación, así como una entrevista en la que se profundizaban y se actualizaba la información derivada de la encuesta aplicada en el 2003.

Con la aplicación de las herramientas metodológicas implementadas en esta segunda investigación pretendemos realizar un diagnóstico del desempeño de los estudiantes al momento de culminar sus estudios universitarios, para comparar estos resultados con los obtenidos en la investigación realizada en el año 2003. El análisis nos permitirá profundizar en el conocimiento de su adscripción a la cultura escrita, sus formas de relacionarse con la tecnocultura contemporánea y las tensiones que se producen entre dichas mediaciones cognitivas en el marco de la formación académica, cuando están próximos a culminar su carrera universitaria

En la prueba de lectura de este segundo proyecto se prestó especial atención a la capacidad de los estudiantes para hacer diferentes tipos de inferencias, así como a los conocimientos procedimentales requeridos para realizar una lectura de doble vía, ascendente y descendente (desde la cognición social del lector hacia el texto y a la inversa), reconociendo las marcas del texto, sus relaciones intertextuales, la presencia de distintos enunciadores y la elaboración implícita de la macroestructura del texto leído, como parte del proceso de comprensión. En la prueba de escritura se evaluó la capacidad para relacionar conocimientos previos con conocimientos nuevos, representar distintos enunciadores según las necesidades del texto escrito, presentar un punto de vista personal y los argumentos que lo sustentan. ${ }^{1}$

En este artículo describimos la prueba de lectura aplicada en la segunda investigación y presentamos el análisis de los resultados obtenidos. Para dicho análisis se consideraron la totalidad de las pruebas aplicadas, aunque sólo 14 de los 20 estudiantes seleccionados fueron entrevistados. 


\section{DESCRIPCIÓN DE LA PRUEBA}

La segunda prueba de lectura seguía las mismas pautas de la prueba del primer proyecto. Consistió en responder un cuestionario de 5 preguntas después de leer el texto "Colombia: crisis política y social”. A continuación presentamos el texto dado a los estudiantes.

\section{COLOMBIA: CRISIS POLÍTICA Y SOCIAL} Por: Ausa

1. Todos los colombianos estamos de acuerdo en que nuestro país atraviesa por una crisis política y social de gran magnitud. Pero no todos estamos de acuerdo en el análisis de la crisis ni en las soluciones que se proponen para resolverla. De hecho, existen diferentes concepciones y miradas acerca del problema.

1.1 Para el presidente Uribe y su gobierno, "en Colombia no hay conflicto, sino una amenaza terrorista contra la democracia"(i). Por lo tanto, es necesario combatir el terrorismo en todas sus manifestaciones, sumándose a la lucha que contra él desarrollan otros países del mundo como Estados Unidos, Inglaterra, España, Italia, sobre todo después de los atentados del once de septiembre. Internamente, este discurso contra el terrorismo se apoya en la frustración provocada por el fracaso de los diálogos de paz en el Caguán durante el gobierno del presidente Pastrana. Así lo reconocieron en su momento las Naciones Unidas cuando expresaron que: "las crecientes críticas y el desencanto de grandes sectores de la población dieron cabida a políticas y estrategias que dan prioridad a respuestas guerreristas"(ii).

1.2 En el extremo opuesto, los grupos guerrilleros - el ELN y las FARC - manifiestan reiteradamente que en nuestro país sí hay un conflicto armado y en ese sentido han desarrollado una estrategia de confrontación política y militar, aunque parece más militar que política, contra el "establecimiento"y sus instituciones representadas por el actual gobierno. Las guerrillas consideran que la injusticia social, la concentración en la propiedad de la tierra, la inequidad en la redistribución del ingreso, y la corrupción, tienen que ser combatidas tanto politica como militarmente para derrocar un régimen que está al servicio de los grandes poderes financieros nacionales y transnacionales; un régimen sometido a las órdenes y a las políticas del imperio norteamericano; un régimen incapaz de resolver los grandes problemas de nuestra sociedad. (iii)

1.3 Otra concepción es la que plantean algunas organizaciones no gubernamentales y la llamada "izquierda democrática” organizada como partido político. Para éstos, en Colombia sí existe un conflicto social y político que se expresa no sólo en la lucha armada que adelantan las guerrillas sino también en la protesta y las movilizaciones de muchos sectores y comunidades que reivindican mejores condiciones de vida, respeto a los derechos civiles, cumplimiento de las obligaciones del estado y neutralidad frente a los actores armados legales e ilegales. Para la "izquierda democrática", los problemas derivados de la injusticia social, la mala distribución de la riqueza y la corrupción no se pueden resolver con la lucha armada ni con la confrontación militar. Estos problemas tienen que enfrentarse por medio de reformas políticas profundas que deben resultar de amplios acuerdos entre diferentes sectores de la sociedad. Sólo mediante negociaciones entre ellos, consensos y pactos con objetivos definidos, es posible encontrar salidas viables al laberinto en que nos encontramos (iv). Sin embargo, esta organización política se encuentra dividida internamente, por lo que es difícil pensar que puedan liderar lo que proponen y sacar adelante sus iniciativas.

1.4 Aparte de las organizaciones politicas hay voces independientes de intelectuales, politólogos, estudiosos y periodistas de nuestro país que continuamente se han pronunciado sobre la crisis y sus manifestaciones. Entre ellos se encuentran Antonio Caballero, Daniel Coronel, Héctor Abad, Carlos Lozano, Felipe Zuleta, Daniel Samper Pizano, María Jimena Dusán y Piedad Bonet.

2. El columnista Antonio Caballero es uno de los que más debate públicamente sobre la crisis de la nación Colombiana a través de sus artículos en algunos medios de comunicación. En un artículo titulado "La realidad y el deseo"(v), Caballero escribió:

"El anuncio lo hace John Ashcroft en persona, el secretario de Justicia de los Estados Unidos, flanqueado solemnemente por el jefe de la DEA, por el 'zar' antidrogas y por el jefe del FBI: su gobierno va a pedir en extradición al 'Mono Jojoy' por porte ilegal de armas. Claro que portar armas no es un delito en los Estados Unidos, al contrario: es el más sagrado de los derechos constitucionales, del que no se puede privar ni siquiera a los asesinos en serie. Pero bueno:Ashcroft también reclama la entrega del jefe guerrillero colombiano por los dos crímenes más tremebundos que existen en el mundo de hoy, que son los crímenes de lesa majestad norteamericana: el tráfico de drogas y el terrorismo. Además de 'Jojoy', y por los mismos motivos, la justicia norteamericana acusa y pide a otros cuantos criminales de las Farc: 'Romaña', el 'Negro Acacio', etc.Y exige también la extradición -sólo por narcotráfico, pero no por terrorismo- de un narcotraficante y terrorista que en el fondo es su aliado, y no su enemigo: el jefe de las autodefensas paramilitares Carlos Castaño".

Más adelante Antonio Caballero continúa su reflexión en los siguientes términos:

"El anuncio del señor Ashcroft provoca en Colombia un gran alboroto de alborozo. Anhela el general Jorge Enrique Mora, comandante de las Fuerzas Militares: "Ojalá a todos esos terroristas se los lleven para allá”. Ofrece Fernando Londoño, el ministro bicéfalo de Interior y Justicia: "Les mandaremos todos los que quieran". Se inclina el presidente Alvaro Uribe: "Colombia acata el ordenamiento jurídico", o sea, lo que diga míster Ashcroft. Un general de tres soles, un ministro de dos cabezas, un presidente de la República: tendrían que ser gente seria ¿no? Pues no. Todos pasan por alto el pequeño detalle de que para extraditar a Castaño o a 'Jojoy' primero hay que cogerlos.Y no los han cogido". 


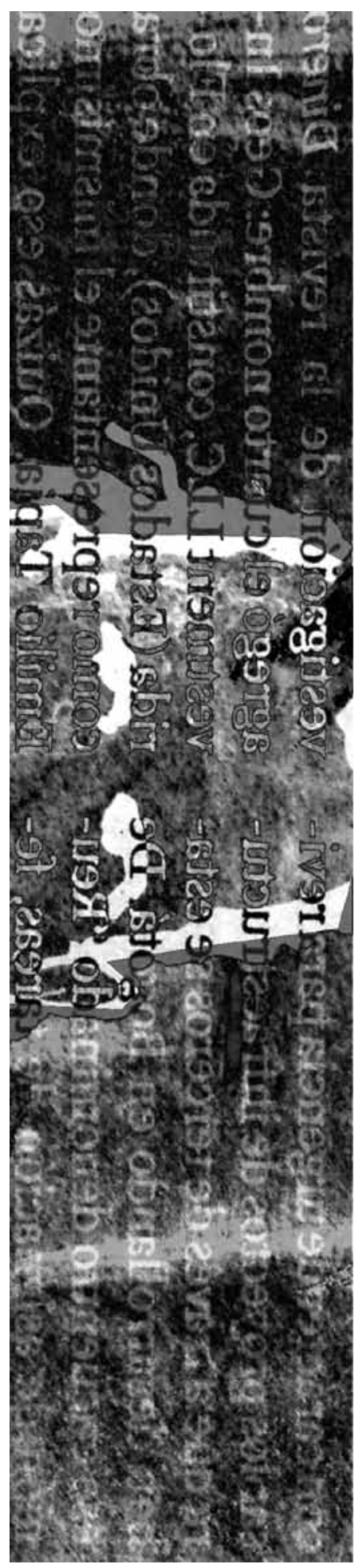

“(Otra gente igual de seria ha anunciado cien veces la muerte de 'Tirofijo'.Y sigue vivo)”.

"Pero es que esperan (anhelan, ofrecen, se inclinan) que a 'jojoi' y a Castaño y a los otros los cojan en su lugar los propios norteamericanos. The New York Times advierte que ya están en eso. Que hay oficiales de los Estados Unidos "entrenando una unidad especial de comandos de 400 hombres para perseguir paramilitares y rebeldes, con énfasis especial en cazar a los jefes", y que el Congreso norteamericano está a punto de aprobar una partida de cinco millones de dólares para ese efecto. Claro que los 150.000 hombres del Ejército colombiano llevan ya medio siglo persiguiendo a esos jefes, y no han podido cazarlos. Pero bueno: los gringos, qué duda cabe, lo harán en un santiamén. ¿Como a Osama Ben Laden? Eeeh? Bueno. El 'Mono Jojoy' y Castaño pueden esperar sentados".

"Ellos pueden estar tranquilos, pero Colombia no. Por culpa, precisamente, de los Estados Unidos, cuya política a la vez infantil y cruel (que viene a ser lo mismo) consiste en jugar con las guerras ajenas como un gato con un ratón. Si ahora acaban de aplastar a los afganos bajo sus bombas 'inteligentes' es porque antes tuvieron la inteligente idea de financiar y armar a los fanáticos talibanes para que lucharan en su lugar contra los soviéticos. Si ahora quieren aniquilar a los iraquies es porque antes armaron a Saddam Hussein para que combatiera la revolución islámica de los ayatolas del Irán. En Colombia han hecho lo mismo, aunque (hasta ahora) en menor escala. Nuestra guerra social es en buena medida producto de la política norteamericana: de la cruzada contra el comunismo primero, de la prohibición de la droga después, y más recientemente del Plan Colombia dirigido contra la droga y contra las guerrillas comunistas. Nuestra guerra tiene orígenes y motivos locales, por supuesto, pero su agravamiento y su prolongación interminable vienen de afuera: del dinero de los drogadictos norteamericanos, que es inmenso gracias a la prohibición, y del dinero de los gobiernos norteamericanos.Y ahora viene este último, el de Bush y su secretario Ashcroft, a cerrarle a Colombia el único camino local para lograr la paz, que es el de negociar la guerra. Si se criminaliza a las fuerzas que la hacen (la guerrilla y los paramilitares, que son las dos sin duda criminales, pero son también fuerzas políticas), si como única perspectiva se les ofrece la cadena perpetua o la pena de muerte en los Estados Unidos ¿quién diablos va a negociar la guerra para buscar la paz?”

Para terminar, el columnista agrega:

"Pero el alboroto alborozado no es sólo de los funcionarios del gobierno. También la gente corriente, desinformada, malinformada, está feliz. “'Viva!”, gritan muchos colombianos desde el fondo de su infortunio: "iPor fin acabaron con el 'Mono Jojoy'!”. Y no. Confunden su deseo con la realidad. Así como eligieron presidente a Alvaro Uribe porque su deseo les hizo confundir una declaración de guerra con un parte de victoria, y antes eligieron a Andrés Pastrana porque su deseo los hizo confundir una fotografía con un tratado de paz, asi confunden ahora una petición jurídica de extradición con una derrota militar de la guerrilla.Y -perdonen que se lo diga- no es lo mismo".

"De manera que tendremos más guerra, y peor. "Vendrán tiempos peores y nos harán más ciegos”, dice, con lucidez implacable, el escritor Rafael Sánchez Ferlosio”.

Los distintos análisis sobre la crisis ponen de manifiesto que el problema es demasiado complejo como para pensar en soluciones simplistas e inmediatas. Ellos indican la presencia de distintos sectores de opinión pública en la vida cotidiana de los colombianos. Así mismo, reflejan la diversidad de intereses en juego, intereses muchas veces antagónicos que dificultan los acercamientos entre las partes. Lo que sí parece claro es que se trata de un conflicto social y político que debe ser resuelto con urgencia. Mientras tanto, la crisis continúa sin que se vislumbre una solución a corto o mediano plazo. 
i. No sólo el presidente lo ha dicho; también sus asesores más cercanos y miembros de su gobierno insisten en esta apreciación que se ha expresado por diferentes medios a lo largo y ancho del territorio nacional.

ii. Informe de la alta comisionada de las Naciones Unidas para los derechos humanos sobre la situación de derechos humanos en Colombia, 2001, página 14. En el mismo documento, la alta comisionada manifiesta que "sólo el compromiso contundente con el Estado de Derecho, las estrategias democráticas y el respeto de los derechos humanos podrá asegurar una convivencia pacífica. Asimismo, recobra renovada vigencia la recomendación del Secretario General de las Naciones Unidas y de la Alta Comisionada relativa a la adopción de un Acuerdo Global de Derechos Humanos y Derecho Internacional Humanitario, como un ingrediente mínimo de un proyecto hacia el cual las partes deben confluir para optar definitivamente por una solución negociada, y sentar los cimientos de una paz firme y duradera”. (Página 15).

iii. El discurso de las FARC se viene repitiendo desde hace más de cuarenta años como parte de una estrategia en la que se "combinan todas las formas de lucha" (participación en elecciones y lucha armada; infiltraciones, retenciones, ajusticiamientos), con lo cual se ha agravado la crisis sin llegar a ninguna solución.

iv. El Polo Democrático ha convocado al gobierno nacional, a los distintos partidos políticos, a las diferentes organizaciones sociales y gremiales "a construir un consenso nacional por la solución política, en torno a cuatro puntos", el primero de los cuales es "el reconocimiento de la existencia en Colombia de un conflicto armado interno de carácter social y político cuya solución debe ser política, mediante acuerdos encaminados tanto a terminar la guerra como a atacar las raíces del conflicto”. (Declaración pública consenso nacional por la solución política. El Polo Democrático Alternativo frente a la paz, Carlos Gaviria Díaz, 2 de Octubre de 2006, en: www. polodemocratico.net).

v. Antonio Caballero, "La realidad y el deseo", Revista Semana, Edición 1072, noviembre 15 de 2002.

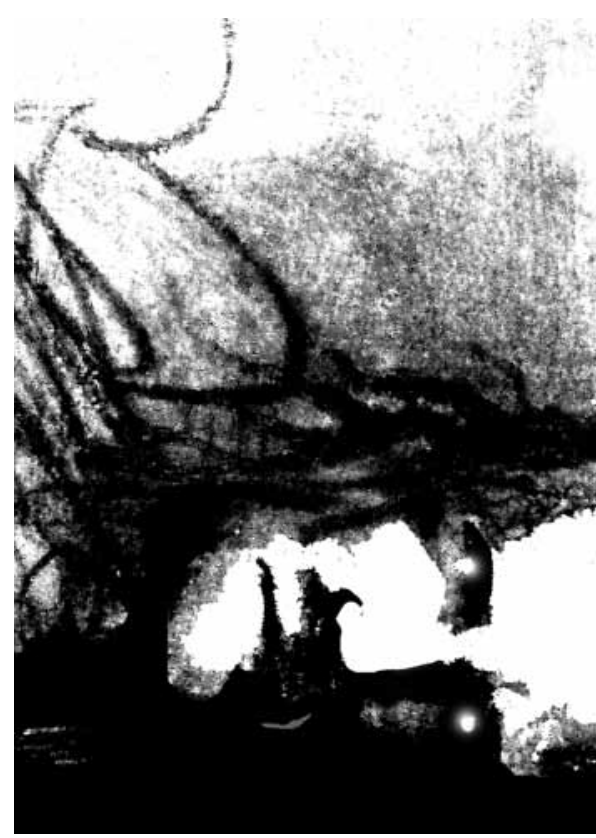

I. Después de leer el texto "Colombia: crisis política y social", responda las siguientes preguntas:

1. El autor del texto:

A. Está a favor del análisis que hace el gobierno del presidente Uribe con respecto a la crisis del país.

B. Está de acuerdo con el análisis que la izquierda democrática hace sobre la crisis colombiana.

C. Está a favor del punto de vista de los grupos guerrilleros acerca de la crisis en nuestro país.

D. No está ni a favor ni en contra de las distintas posiciones expuestas en el texto sobre la crisis del país.

2. Frente a la crisis colombiana el periodista Antonio Caballero aboga por:
A. Una solución militar apoyada por todas las fuerzas políticas y la ciudadanía del país.
B. Una solución negociada con la intervención directa de los Estados Unidos.
C. Una solución negociada con la intervención indirecta de los Estados Unidos.
D. Una solución militar sin ninguna clase de intervención de los Estados unidos.
E. Ninguna de las anteriores.

3. En su pronunciamiento sobre la situación colombiana, las Naciones Unidas
A. Están de acuerdo con el gobierno colombiano con respecto a la solución militar y guerrerista de la crisis.
B. Se oponen a los planteamientos del periodista Antonio Caballero.
C. Comparten el mismo punto de vista de las guerrillas.
D. Se oponen a la solución militar y guerrerista de la crisis.
E. Apoyan a grandes sectores de la población que dieron cabida a políticas y estrategias guerreristas 
4. El periodista Antonio Caballero califica a las guerrillas y a los grupos paramilitares como criminales.

Por lo tanto considera que:
A. Se deben capturar y extraditar a los Estados Unidos
B. Se debe apoyar a los Estados Unidos para que los capture
C. No se debe negociar con ellos sino combatirlos
D. Se debe negociar con ellos pero con la participación de Estados Unidos
E. Ninguna de las anteriores.

5. Según el texto leído, se puede concluir que:
A. Para Antonio Caballero, los norteamericanos son los únicos capaces de capturar a los cabecillas de la guerrilla y los grupos paramilitares.
B. El autor comparte la estrategia de confrontación de los grupos guerrilleros
C. Antonio Caballero plantea que las soluciones propuestas por el gobierno contradicen el deseo de los colombianos
D. La izquierda democrática comparte los planteamientos de los grupos guerrilleros
E. Antonio Caballero está en contra de la extradición de los cabecillas de la guerrilla y de los grupos paramilitares.

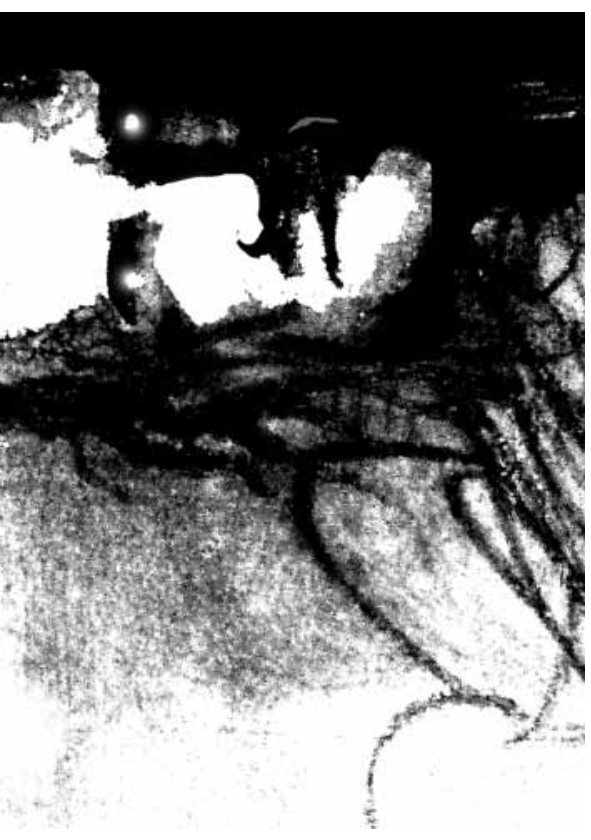

\section{OBJETIVOS DE LA PRUEBA DE LECTURA}

Uno de los objetivos generales de nuestra investigación, fue conocer el grado de adscripción de los sujetos de la investigación a la cultura escrita y su grado de pertenencia a la tecnocultura contemporánea, e identificar posibles relaciones de tensión o de complementariedad entre ambas. En lo que respecta a la cultura escrita, nos propusimos realizar un diagnóstico del desempeño de los estudiantes en la lectura y escritura de textos expositivos-argumentativos, al momento de finalizar su carrera universitaria. Esto con el fin de establecer una comparación con los resultados obtenidos por ellos mismos en las pruebas presentadas en la investigación realizada en el año 2003.

En consonancia con lo anterior, la prueba de lectura diseñada se propuso indagar en qué medida los estudiantes sujetos de la investigación poseen y aplican los conocimientos procedimentales propios de la cultura escrita ${ }^{2}$. En ese sentido la prueba se proponía diagnosticar la capacidad de los estudiantes para:

1. Leer desde la perspectiva de la organización del texto y no sólo desde la perspectiva del lector y su cognición social.

2. Relacionar sus conocimientos previos (semánticos y procedimentales) con los conocimientos nuevos aportados por el texto. ${ }^{3}$

Este modo de leer, requiere poner en acción (si se poseen) los siguientes conocimientos procedimentales en función de la prueba de lectura diseñada para esta investigación:

a. Realizar inferencias a partir de la relación entre conocimientos previos y conocimientos nuevos. La capacidad de inferir ligada a la lectura del texto verbal es también un conocimiento procedimental de la cultura escrita.

b. Identificar y reconocer el enunciador dominante, con sus respectivos enunciados, y diferenciarlo de los enunciadores referidos, no como un acto aislado sino en función de la significación global del texto y de sus significados particulares.

(Esto último es igualmente válido para los siguientes literales).

c. Identificar y reconocer los enunciadores referidos con sus respectivos enunciados.

d. Identificar y reconocer las paráfrasis, las ironías, los discursos directos e indirectos adscritos a sus respectivos enunciadores. 
e. Identificar y reconocer los puntos de vista, explícitos o no, de cada uno de los enunciadores presentes en el texto.

f. Reconocer la Macroestructura del texto general ("Colombia, crisis política y social”) y diferenciarla de la macroestructura del texto de Antonio Caballero ("La Realidad y el deseo").

g. Reconocer la Macroestructura del texto de Antonio Caballero, incluido en el texto general.

h. Reconocer las superestructuras del texto expositivo-argumentativo

(problema- solución, paralelismo y contraste, tesis y argumentos, relaciones de causa-efecto)

Insistimos en la necesidad de considerar los conocimientos previos de carácter procedimental, propios de la cultura escrita, que se requieren para leer desde la perspectiva de la organización del texto.Y es esto lo que estamos evaluando: si el estudiante posee o no tales conocimientos. En el diseño de la prueba asumimos que se trata de jóvenes colombianos, estudiantes universitarios que tienen una información sobre el tema (conocimientos semánticos), así como sus propias opiniones. Sin embargo, aclaramos que el propósito de la prueba de lectura no era el análisis de sus opiniones, aspecto que sí fue considerado en la prueba de escritura. En ésta, les solicitamos elaborar "una reflexión personal sobre la situación actual de la crisis colombiana teniendo en cuenta el texto leído".

\section{CARACTERIZACION DE LA PRUEBA}

El texto empleado en esta segunda prueba de lectura fue creado por los investigadores, tratando de que fuera semejante al de la primera prueba, no tanto por su contenido sino por su estructura enunciativa y por su carácter expositivo-argumentativo. En este sentido, es un ensayo que presenta varias superestructuras como Comparación y Contraste cuando describe las diferentes concepciones que tienen los actores mencionados frente al "conflicto colombiano". Problema-Solución, cuando identifica ese conflicto y explica las diversas "soluciones" propuestas por los actores involucrados. Tesis-Argumentos, cuando fija una posición propia y se distancia de cada uno de ellos. Como se apreciará más adelante, esta superestructura es más visible en el artículo de Antonio Caballero insertado como parte del ensayo. Ahora bien, estas y las demás superestructuras que lo componen están inmersas en una estructura enunciativa que las integra como elementos retóricos característicos de los textos expositivoargumentativos. A diferencia del modelo de Van Dyjk - y de la lingüística textual basada en él - que ignora la teoría de la enunciación para la comprensión textual, aquí la reivindicamos como una condición sin e quanon. De ahí que nuestra perspectiva teórica y metodológica se propone relacionar los dos modelos de manera complementaria con el fin de observar sus imbricaciones, cómo se superponen y participan del proceso comprensivo y cognitivo que implica toda lectura.

Con relación a la estructura enunciativa, el ensayo de la prueba presenta un enunciador dominante en forma impersonal que distribuye los turnos a diversos enunciadores referidos, cada uno de los cuales expresa sus puntos de vista frente a un problema descrito. De esta manera, se presenta la intertextualidad y la confrontación de diversos puntos de vista con sus respectivos argumentos. La intertextualidad se manifiesta a través del discurso directo y mediante el discurso indirecto, la paráfrasis y la ironía, que deben ser inferidas por el lector. Esta exigencia -la de producir inferencias para comprender el texto y contestar acertadamente las preguntas del cuestionario- también estuvo presente en la prueba diseñada para la primera investigación. Para poder inferir, el lector debe identificar y diferenciar el enunciador dominante, los enunciadores referidos y sus respectivos enunciados y puntos de vista. En el cuestionario, las preguntas estaban dirigidas a indagar, indirectamente, por estos aspectos que hacen parte de los conocimientos procedimentales propios de la cultura escrita, teniendo en cuenta que éste es uno de los objetivos del proyecto.

\section{Caracterización del texto de la prueba en términos de la estructura enunciativa}

El texto producido consta de dos partes marcadas numéricamente (1 y 2). En la primera, el enunciador dominante -que representa al autor (Ausa)- cita varios enunciadores referidos (el presidente Álvaro Uribe, las Naciones Unidas, las guerrillas ELN y FARC, la izquierda democrática, "voces independientes", intelectuales, periodistas y otros). El enunciador dominante le atribuye a cada uno de los referidos, unos enunciados. Esta primera parte, a su vez, está subdividida en cuatro secciones, debidamente identificadas.

En la segunda parte del texto el enunciador dominante cita textualmente un artículo de Antonio Caballero ("La realidad y el deseo") que tiene a su vez un enunciador dominante y varios enunciadores referidos (John Ashcroft, Jorge Enrique Mora, 
Fernando Londoño, Álvaro Uribe, "otra gente igual de seria”, the New York Times, "la gente corriente” y Rafael Sánchez).

Tanto el enunciador dominante del texto principal (Ausa), como el enunciador dominante de "La realidad y el deseo" (Antonio Caballero), atribuyen a cada uno de los enunciadores referidos unos enunciados, que citan mediante el discurso directo o mediante el discurso indirecto y la paráfrasis. Es necesario señalar el contraste evidente entre ambos enunciadores dominantes puesto que el primero, representado en forma impersonal, se mantiene como una especie de observador "objetivo", "neutral”, excepto cuando se incluye como parte de un colectivo al afirmar:

"Todos los colombianos estamos de acuerdo en que en nuestro país atraviesa por una crisis política y social de gran magnitud. Pero no todos estamos de acuerdo en el análisis de la crisis ni en las soluciones que se proponen para resolverla”. El segundo enunciador dominante que representa a Antonio Caballero asume la primera persona, de manera constante, para fijar su punto de vista abiertamente mediante recursos como la paráfrasis y la ironía, de la cual hace gala.

En el texto dado ("Colombia: crisis política y social"), el enunciador dominante cumple la función de distribuir los turnos y presentar los enunciadores referidos sin tomar partido por ninguno de ellos ("Para el presidente Uribe y su gobierno..."

"En el extremo opuesto, los grupos guerrilleros... 'Otra concepción es la que plantean algunas organizaciones no gubernamentales y la llamada izquierda democrática..."). Al representarse en una forma impersonal que predomina en el texto, sugiere una "neutralidad" en tanto se limita a presentar las posiciones de los diferentes actores que cita. Aunque sí expresa un punto de vista propio con respecto al conflicto colombiano, el enunciador dominante no adhiere a ninguna de las posiciones expresadas por los enunciadores referidos.

El punto de vista del enunciador dominante se manifiesta explícitamente en tres fragmentos: uno, en el primer párrafo, ya citado (“Todos los colombianos estamos de acuerdo en que..."). Otro, en el que fija su posición sobre la Izquierda democrática cuando dice:

"Sin embargo, esta organización política se encuentra dividida internamente, por lo que es difícil pensar que puedan liderar lo que proponen y sacar adelante sus iniciativas”.
Y finalmente, su punto de vista se explicita en el último párrafo cuando enuncia:

"Los distintos análisis sobre la crisis ponen de manifiesto que el problema es demasiado complejo como para pensar en soluciones simplistas e inmediatas. Ellos indican la presencia de distintos sectores de la opinión pública en la vida cotidiana de los colombianos. Así mismo, reflejan la diversidad de intereses en juego, intereses muchas veces antagónicos que dificultan los acercamientos entre las partes. Lo que sí parece claro, es que se trata de un conflicto social y político que debe ser resuelto con urgencia. Mientras tanto, la crisis continúa sin que se vislumbre una solución a corto o mediano plazo".

Ahora bien, el enunciador dominante le da más despliegue al periodista Antonio Caballero, uno de los enunciadores referidos. Citar la columna completa podría ser tomado como un indicio de falta de neutralidad del enunciador dominante -dada la notable extensión del artículo citado-. Sin embargo, aparte de este indicio no hay evidencia alguna que permita llegar a esa conclusión. Y el indicio, aunque justificado, por sí sólo no es suficiente.

El texto contiene cinco notas de pie de página, las cuales cumplen la función de ampliar las ideas expuestas además de documentar la fuente de información consultada. Consideramos que dichas notas, en tanto marcas textuales, deben ser leídas y articuladas al proceso de representación semántica (construcción del mapa mental del significado) como parte de la comprensión textual. Leer desde la perspectiva de la organización del texto exige leer las notas pie de página y tenerlas en cuenta para responder el cuestionario y elaborar la reflexión que pedía la prueba de escritura.

Las notas fueron colocadas al final - y no al pie de página - como una decisión deliberada, para indagar qué tanta importancia le daban los estudiantes. En éste como en la mayoría de textos expositivo-argumentativos canónicamente escritos, dichas notas aportan no sólo información complementaria sino también información necesaria para la producción de inferencias. Su empleo hace parte de la escritura canónica propia de los ámbitos académicos y científicos y como tal es una marca de la cultura escrita contemporánea.

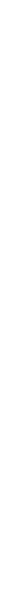




\section{RESULTADOSY ANÁLISIS DE LAS RESPUESTAS DE LOS ESTUDIANTES}

\section{Pregunta 1:}

El autor del texto "Colombia: crisis política y social":

A. Está a favor del análisis que hace el gobierno del presidente Uribe con respecto a la crisis del país.

B. Está de acuerdo con el análisis que la izquierda democrática hace sobre la crisis colombiana.

C. Está a favor del punto de vista de los grupos guerrilleros acerca de la crisis en nuestro país.

D. No está ni a favor ni en contra de las distintas posiciones expuestas en el texto sobre la crisis del país.

Responder esta pregunta correctamente implicaba identificar el punto de vista del autor con respecto al problema colombiano descrito en el texto. El autor está representado por el enunciador dominante y su punto de vista se diferencia de los otros puntos de vista de los enunciadores referidos. Como ya está dicho, el autor no adhiere a ninguno de ellos. Por lo tanto la respuesta correcta es la (D).

De los 20 estudiantes que presentaron la prueba, 16 respondieron correctamente. Los 4 que erraron respondieron (B): el autor "Está de acuerdo con el análisis que la izquierda democrática hace sobre la crisis colombiana".

Probablemente, quienes respondieron así se basaron en el título del texto dado y en el reconocimiento que el autor hace de la crisis política y social que vive el país (párrafo 1), lo cual reitera al final cuando alude a un conflicto social y político. Vistos de manera aislada, en estos fragmentos se puede encontrar una coincidencia con el punto de vista de la izquierda democrática. Sin embargo, el análisis de la izquierda no se reduce a dicha descripción pues además habla de las causas del conflicto, sus manifestaciones y la forma como debería enfrentarse la crisis. El enunciador dominante no entra en estas consideraciones, lo cual no parece haber sido percibido por los estudiantes que respondieron la opción B. Lo anterior significa que los estudiantes no relacionaron los fragmentos citados con el párrafo en el cual el autor toma distancia frente al posible liderazgo de la izquierda democrática para sacar adelante su proyecto político (final del párrafo 1.3, cuando dice: "Sin embargo, esta organización política se encuentra dividida internamente, por lo que es difícil pensar que puedan liderar lo que proponen y sacar adelante sus iniciativas”. Los estudiantes que seleccionaron la opción B no percibieron tampoco o no tuvieron en cuenta esa toma de distancia. Además, pasaron por alto que en el texto no hay una marca explícita de la adhesión del autor (el enunciador dominante) al análisis que la izquierda democrática hace sobre la crisis colombiana. En conclusión, no hay en el texto las marcas necesarias para asumir que el autor está de acuerdo con el análisis de la izquierda democrática. Creemos que quienes se equivocaron no realizaron una lectura desde la perspectiva de la organización del texto, específicamente para esta pregunta.

\section{Pregunta 2:}

Frente a la crisis colombiana el periodista Antonio Caballero aboga por:
A. Una solución militar apoyada por todas las fuerzas políticas y la ciudadanía del país.
B. Una solución negociada con la intervención directa de los Estados Unidos.
C. Una solución negociada con la intervención indirecta de los Estados Unidos.
D. Una solución militar sin ninguna clase de intervención de los Estados Unidos.
E. Ninguna de las anteriores. 
Esta pregunta indagaba por la tesis de Antonio Caballero (uno de los enunciadores referidos). Responderla correctamente implicaba (1) Identificar el punto de vista de este enunciador con respecto al problema colombiano descrito en el texto y (2) Reconocer la macroestructura del artículo de Antonio Caballero, para quien la solución a la crisis debe ser un acuerdo negociado sin ninguna clase de intervención de los Estados Unidos.

Considerado de manera relativamente autónoma, el texto de Caballero tiene un enunciador dominante que representa el autor. Así mismo, como ya lo hemos dicho, contiene varios enunciadores referidos citados a lo largo del artículo.

$\mathrm{Al}$ analizar los resultados, encontramos que 17 de los 20 estudiantes respondieron esta pregunta de manera acertada (opción E). Dos estudiantes marcaron la opción C y otro marcó la D.

Tanto en la opción C como en la D hay sendos distractores que pudieron "inducir" al error. A ellos, haremos referencia a continuación.

En (C) se habla de una solución negociada, como efectivamente lo propone el articulista cuando afirma que "el único camino local para lograr la paz es el de negociar la guerra". Sin embargo, el autor no está de acuerdo con ningún tipo de intervención norteamericana, según se infiere de sus apreciaciones sobre la política de Estados Unidos que consiste en "jugar con las guerras ajenas como un gato con un ratón”. A lo largo de su artículo hay permanentes críticas al gobierno norteamericano por sus intervenciones militares en distintos países, incluido Colombia. "Nuestra guerra social es en buena medida producto de la política norteamericana..." afirma en una parte de su texto. Más adelante agrega que "Si se criminaliza a las fuerzas que la hacen (la guerrilla y los paramilitares, que son las dos sin duda criminales, pero son también fuerzas políticas), si como única perspectiva se les ofrece la cadena perpetua o la pena de muerte en los Estados Unidos ¿quién diablos va a negociar la guerra para buscar la paz?”.

Consideramos que estos fragmentos al lado de otros igualmente significativos, dan pie para deducir que él está en contra de cualquier tipo de intervención. Por lo tanto, la opción C queda descartada.

Con respecto a la opción D, hay otro distractor: si bien Antonio Caballero cuestiona la intervención norteamericana, (lo cual sí se manifiesta en dicha opción) él no está de acuerdo con una salida militar del conflicto cuando dice que "el único camino local para lograr la paz es el de negociar la guerra". Por ello, al decir que Antonio Caballero aboga por una solución militar, la opción D no expresa su punto de vista sobre la crisis colombiana.

Creemos que las respuestas erradas obedecen a un análisis incompleto en la medida en que los distractores no se reconocieron como tales, en función de una lectura desde la perspectiva de la organización del texto.

Para responder acertadamente la segunda pregunta era necesario entonces producir una inferencia, y para hacerla se requería relacionar conocimientos previos con la información contenida en el texto. Podemos suponer que quienes seleccionaron la opción $\mathrm{C}$ o la $\mathrm{D}$ no relacionaron esos conocimientos, o no leyeron desde la perspectiva de la organización del texto, al responder esta pregunta. 


\section{Pregunta 3:}

En su pronunciamiento sobre la situación colombiana, las Naciones Unidas:

A. Están de acuerdo con el gobierno colombiano con respecto a la solución militar y guerrerista de la crisis.

B. Se oponen a los planteamientos del periodista Antonio Caballero.

C. Comparten el mismo punto de vista de las guerrillas.

D. Se oponen a la solución militar y guerrerista de la crisis.

E. Apoyan a grandes sectores de la población que dieron cabida a políticas y estrategias guerreristas

Esta pregunta indagaba por el punto de vista de las Naciones Unidas como otro de los enunciadores referidos, y la relación entre éste y los demás puntos de vista. Para responder correctamente, se requería identificar a las Naciones Unidas como un enunciador referido con su punto de vista frente al conflicto. En el párrafo 1.1 se introduce el enunciador Naciones Unidas. Mediante una paráfrasis de la declaración de la ONU, el enunciador dominante explica que "el discurso contra el terrorismo en Colombia se apoya en la frustración provocada por el fracaso de los diálogos de paz en el Caguán durante el gobierno del presidente Pastrana”.Y luego, para constatar su paráfrasis, cita textualmente la declaración: "Las crecientes críticas y el desencanto de grandes sectores de la población dieron cabida a políticas y estrategias que dan prioridad a respuestas guerreristas...”.

El texto continúa con un llamado de pie de página en el que se concreta de manera explícita la posición de las Naciones Unidas, en este caso mediante el discurso directo:

$<<$ La alta comisionada manifiesta que "sólo el compromiso contundente con el Estado de Derecho, las estrategias democráticas y el respeto de los derechos humanos podrá asegurar una convivencia pacífica. Asimismo, recobra renovada vigencia la recomendación del Secretario General de las Naciones Unidas y de la Alta Comisionada, relativa a la adopción de un Acuerdo Global de Derechos Humanos y Derecho Internacional Humanitario, como un ingrediente mínimo de un proyecto hacia el cual las partes deben confluir para optar definitivamente por una solución negociada, y sentar los cimientos de una paz firme y duradera" $>>$.

De acuerdo con este enunciado, la respuesta correcta es la opción D (Las Naciones Unidas se oponen a la solución militar y guerrerista de la crisis colombiana). Para llegar a esta conclusión no es necesario hacer una inferencia compleja; es suficiente con una inferencia automática. De todos modos, es imprescindible leer el pie de página (ii), a partir del cual elaborar la inferencia.

Una vez evaluadas las pruebas, encontramos que catorce de los veinte estudiantes respondieron acertadamente, cinco respondieron incorrectamente y uno no respondió.

Tres de los que respondieron de manera equivocada seleccionaron la opción A ("Las Naciones Unidas están de acuerdo con el gobierno colombiano con respecto a la solución militar y guerrerista de la crisis"). Quizás esta respuesta obedece parcialmente a la manera como el enunciador dominante introduce el fragmento del informe de la alta comisionada de las Naciones Unidas: "Así lo reconocieron en su momento las Naciones Unidas cuando expresaron que (...)”. De la expresión subrayada no se puede inferir que la ONU esté de acuerdo con una salida militar y guerrerista al conflicto colombiano. El marcador deíctico “Así” indica que para las Naciones Unidas "el discurso contra el terrorismo" es una consecuencia de la frustración generada en el país por el fracaso de los diálogos de paz durante el Gobierno de Andrés Pastrana, posición que se puede constatar al leer la cita textual que se encuentra a continuación. Es el pie de página el lugar donde se manifiesta, de manera explícita, la posición de las Naciones Unidas en cuanto a la necesidad de encontrar una solución negociada al conflicto. Podemos suponer que los estudiantes que respondieron la opción A no leyeron la nota de pie de página o lo hicieron sin prestarle atención. En este sentido, no relacionaron la información previa con la información nueva aportada en el pie de página; y esto significa no leer desde la perspectiva de la organización del texto. 
En cuanto a los dos estudiantes que señalaron la opción E (las Naciones Unidas apoyan a grandes sectores de la población que dieron cabida a políticas y estrategias guerreristas), encontramos lo siguiente: Dichos estudiantes también pasaron por alto la información contenida en el pie de página y por eso no relacionaron la información previa con la información nueva aportada por él. Además, asumieron que la expresión que antecede la cita textual con la que se cierra el párrafo 1.1 se puede interpretar como un respaldo a los sectores de la población que apoyan políticas y estrategias guerreristas. Así mismo, habrían entendido la explicación que dan las Naciones Unidas al auge del discurso contra el terrorismo (consecuencia de la frustración generada por el fracaso de los diálogos en el Caguán) como un apoyo a las políticas y estrategias guerreristas. En otras palabras, no percibieron que tal explicación hace parte de la información contextual necesaria para situar el problema.

Como lo expresamos anteriormente, la inclusión de notas de pie de página tenía como propósito identificar si los estudiantes les conceden importancia a la hora de leer y la incidencia que esto tiene en la lectura desde la perspectiva de la organización del texto. Como hemos podido constatarlo con esta pregunta, la lectura del pie de página es fundamental para construir parte de la macroestructura del texto leído, en este caso relacionada con la identificación de los puntos de vista presentes en el texto y las relaciones entre ellos.

\section{Pregunta 4:}

El periodista Antonio Caballero califica a las guerrillas y a los grupos paramilitares como criminales. Por lo tanto considera que:

A. Se deben capturar y extraditar a los Estados Unidos

B. Se debe apoyar a los Estados Unidos para que los capture

C. No se debe negociar con ellos sino combatirlos

D. Se debe negociar con ellos pero con la participación de Estados Unidos

E. Ninguna de las anteriores.

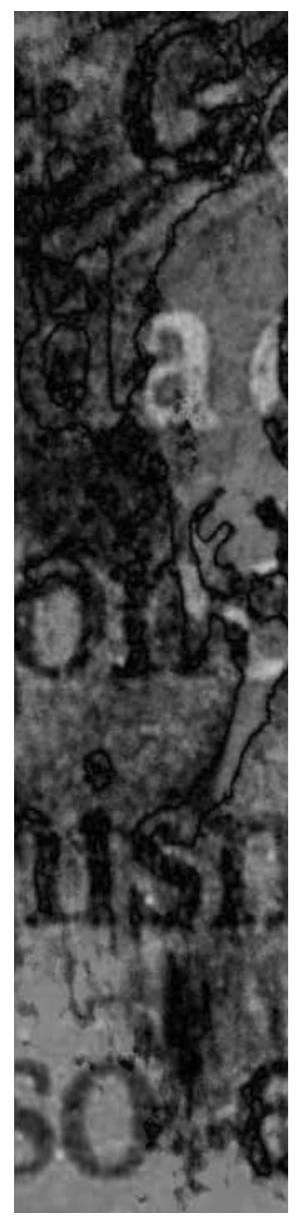

Esta pregunta estaba relacionada con la identificación del punto de vista de Antonio Caballero acerca de las guerrillas y los grupos paramilitares. Para responderla era necesario diferenciar el enunciador que representa a Caballero, de los demás enunciadores referidos por él. Además, era indispensable identificar cuál es su posición frente a la extradición de los cabecillas; frente al eventual apoyo de los Estados Unidos para su captura; frente al carácter político ( y no sólo criminal ) de las organizaciones guerrilleras y paramilitares; y frente a la participación o no de los Estados Unidos en la negociación con estas organizaciones. Si examinamos cada uno de estos tópicos, nos damos cuenta de que Caballero:

a) Se opone a la extradición cuando afirma que: "Si se criminaliza a las fuerzas que hacen [la guerra] (la guerrilla y los paramilitares, que son las dos sin duda criminales, pero son también fuerzas políticas), si como única perspectiva se les ofrece la cadena perpetua o la pena de muerte en los Estados Unidos ¿quién diablos va a negociar la guerra para buscar la paz?”

De este argumento y la pregunta enunciada se infiere que él está en contra de la extradición de los jefes guerrilleros y paramilitares, aunque no lo diga de manera explícita.

b) Pone en duda la capacidad de los norteamericanos para capturar a los cabecillas de la guerrilla y de los grupos paramilitares. Esa puesta en duda se logra mediante una ironía cuando alude a la captura de Osama Ben Laden, quien hasta ahora no ha sido detenido. Para ello Caballero acude a una pregunta retórica donde se concentran la ironía y el cuestionamiento: 
"Pero bueno: los gringos, qué duda cabe, lo harán en un santiamén. ¿Como a Osama Ben Laden? Eeeh? Bueno. El 'Mono Jojoy' y Castaño pueden esperar sentados”.

c) Afirma que a pesar de ser criminales, la guerrilla y los paramilitares son también fuerzas políticas. Por lo tanto, es necesario negociar la guerra con ellos como el único camino para lograr la paz.

d) Como ya se explicó anteriormente en el análisis de la pregunta 2, Caballero se opone a cualquier tipo de intervención norteamericana, a la que le atribuye el agravamiento del conflicto, cuando dice:

"Nuestra guerra social es en buena medida producto de la política norteamericana: de la cruzada contra el comunismo primero, de la prohibición de la droga después, y más recientemente del Plan Colombia dirigido contra la droga y contra las guerrillas comunistas. Nuestra guerra tiene orígenes y motivos locales, por supuesto, pero su agravamiento y su prolongación interminable vienen de afuera: del dinero de los drogadictos norteamericanos, que es inmenso gracias a la prohibición, y del dinero de los gobiernos norteamericanos".

Con base en este análisis, la respuesta correcta es la opción E (Ninguna de las anteriores)

Para llegar a esta conclusión era necesario correlacionar diferentes fragmentos del texto de Caballero con el enunciado de la pregunta y con las opciones de respuesta. También se requería relacionar información previa con información nueva, incluidas las connotaciones expresadas en las paráfrasis, las ironías y las preguntas de Caballero. En otras palabras, era menester identificar la ironía como tal, reconocer su fuerza ilocutiva ${ }^{4}$ y el potencial crítico expresado en ellas. La capacidad para lograr esto es también un conocimiento procedimental de la cultura escrita y hacia allá estaba dirigida la pregunta en particular y la prueba en general.

De los 20 estudiantes, 18 respondieron correctamente la pregunta 4. Los que se equivocaron, escogieron la opción D según la cual en Colombia se debe negociar con los paramilitares y la guerrilla, pero con la participación de Estados Unidos. Probablemente la elección de esta respuesta obedece a que era la única opción que mencionaba la necesidad de negociar, planteada por Caballero. Pero, pasaron por alto el hecho de que él está en contra de la intervención norteamericana. Esta omisión puede ser producto de una lectura que no relacionó las diferentes partes del texto, o no reconoció el valor de la ironía, ni la fuerza ilocutiva de las preguntas de Caballero, ni la connotación de las paráfrasis a través de las cuales el autor se opone a dicha intervención.

\section{Pregunta 5:}

Según el texto leído, se puede concluir que:

A. Para Antonio Caballero, los norteamericanos son los únicos capaces de capturar a los cabecillas de la guerrilla y los grupos paramilitares.

B. El autor comparte la estrategia de confrontación de los grupos guerrilleros.

C. Antonio Caballero plantea que las soluciones propuestas por el gobierno contradicen el deseo de los colombianos

D. La izquierda democrática comparte los planteamientos de los grupos guerrilleros

E. Antonio Caballero está en contra de la extradición de los cabecillas de la guerrilla y de los grupos paramilitares. 
Responder esta pregunta implicaba, una vez más, identificar los enunciadores y los puntos de vista presentes en el texto para relacionarlos entre sí y reconocer sus diferencias. En otras palabras, era necesario tener claridad sobre la posición del enunciador dominante (que representa al autor -Ausa-) frente a los grupos guerrilleros, descubrir si se identifica o se distancia de ellos. Para hacerlo, el lector debe percibir y relacionar las pistas (marcas verbales) que el texto ofrece. Así mismo, el lector debe captar la posición de la izquierda democrática frente a los grupos guerrilleros de acuerdo con lo dicho en el texto. Si bien la cognición social del lector no es ajena al debate público sobre un tema tan polémico (por ejemplo, puede existir en sectores de opinión la idea de una actitud ambigua por parte de la izquierda democrática con respecto a la guerrilla), las preguntas no estaban dirigidas a conocer su opinión sino su capacidad para realizar inferencias, relacionar entre sí los distintos contenidos del texto, reconocer sus marcas verbales y ejercer una lectura en doble vía, ascendente y descendente. Con respecto a las tres opciones de respuesta que implican a Antonio Caballero, era necesario inferir cuál es su posición, expresada en su artículo, frente a los norteamericanos, el gobierno colombiano, las guerrillas y los paramilitares.

La respuesta correcta es la E, pues, según lo explicamos en el análisis de la pregunta 4, el autor de "La realidad y el deseo" considera que la extradición de los jefes de la guerrilla y de los grupos paramilitares impediría llegar a una solución negociada del conflicto. A lo largo del análisis se verá por qué las otras opciones no corresponden a la información contenida en el texto.

De acuerdo con los resultados, la pregunta 5 fue la que tuvo un mayor porcentaje de desaciertos: nueve de los veinte estudiantes se equivocaron al responderla. Siete estudiantes señalaron la opción $\mathrm{C}$, uno respondió la $\mathrm{B}$ y otro la $\mathrm{D}$.

Tomemos la opción C y veamos cuáles pueden ser las razones que tuvieron algunos estudiantes para señalarla como la respuesta correcta:

Entre las cinco opciones de respuesta, estos estudiantes se inclinaron por aquella que contenía una parte del título del texto de Caballero ("La realidad y el deseo"). Por otro lado, la selección de esta opción está conectada con la crítica que Caballero hace al gobierno.

Caballero cuestiona al gobierno cuando dice:

"El anuncio del señor Ashcroft provoca en Colombia un gran alboroto de alborozo. Anhela el general Jorge Enrique Mora, comandante de las Fuerzas Militares: "Ojalá a todos esos terroristas se los lleven para allá". Ofrece Fernando Londoño, el ministro bicéfalo de Interior y Justicia: "Les mandaremos todos los que quieran". Se inclina el presidente Álvaro Uribe:"Colombia acata el ordenamiento jurídico”, o sea, lo que diga mister Ashcroft. Un general de tres soles, un ministro de dos cabezas, un presidente de la República: tendrían que ser gente seria ¿no? Pues no. Todos pasan por alto el pequeño detalle de que para extraditar a Castaño o a 'Jojoy' primero hay que cogerlos. Y no los han cogido"(...).

(...) Claro que los 150.000 hombres del Ejército colombiano llevan ya medio siglo persiguiendo a esos jefes, y no han podido cazarlos. Pero bueno: los gringos, qué duda cabe, lo harán en un santiamén.

¿Como a Osama Ben Laden? Eeeh? Bueno. El 'Mono Jojoy' y Castaño pueden esperar sentados”.

Luego de identificar estas críticas, los estudiantes que optaron por C probablemente hicieron la siguiente deducción: si el autor cuestiona al gobierno, eso significa que las soluciones propuestas por éste "contradicen el deseo de los colombianos" (la paz, la finalización de la guerra, el triunfo del Estado sobre las fuerzas al margen de la ley, la captura de los jefes guerrilleros y paramilitares, en fin...). Ello reforzaría su idea de que la $\mathrm{C}$ es la respuesta correcta. 
Por otra parte, el estudiante que respondió "B", pudo haber interpretado que al hablarse del autor se estaba haciendo referencia a Caballero, y no al autor del texto "Colombia: crisis política y social" (Ausa). La confusión pudo presentarse por la contigüidad que hay entre los dos términos (“Antonio Caballero” en la opción A y “el autor” en la opción B).

Si fue así, y respondió B pensando que se trataba de Antonio Caballero, pudo prevalecer en el estudiante una idea preconcebida (como parte de su cognición social) con respecto a este periodista, quien es percibido por algunos sectores de la opinión pública, como un supuesto aliado de los grupos guerrilleros. De haber sido así, el estudiante en cuestión pasó por alto el fragmento del texto en el cual Antonio Caballero critica duramente a la guerrilla, a la que considera tan criminal como a los paramilitares, no obstante reconocer que ambas son fuerzas políticas. Esto significa que el estudiante hizo una lectura en una sola vía (descendente) y no leyó desde la perspectiva de la organización del texto, por lo menos en relación con esta pregunta.

Si no hubo tal confusión entre el autor (Ausa) y Antonio Caballero, hay indicios para pensar que el estudiante se orientó por el contenido del párrafo 1.2. En él, Ausa se refiere a una serie de circunstancias que, según la guerrilla, explicarían la existencia del conflicto y justificarían tanto la confrontación política como la militar de los rebeldes contra el régimen. El estudiante, entonces, no reconoció que se trataba de una paráfrasis del discurso de la guerrilla, divulgado desde hace varias décadas. Paráfrasis que era necesario inferir a partir de los verbos ilocutivos ("los grupos guerrilleros manifiestan"; "las guerrillas consideran que"). Estas huellas verbales operan como marcadores de distanciamiento del autor frente al punto de vista de estos actores armados. Al no inferir que se trataba de una paráfrasis, el estudiante no habría diferenciado el punto de vista de los alzados en armas, del punto de vista del autor, quien toma distancia frente a ellos y por lo tanto no se identifica con sus planteamientos. Esa toma de distancia se expresa en dos momentos: en el párrafo 1.2 cuando dice que la estrategia de la guerrilla "parece más militar que política", y de manera más explícita en el pie de página número (iii) donde afirma que "El discurso de las FARC se viene repitiendo desde hace más de cuarenta años como parte de una estrategia en la que se 'combinan todas las formas de lucha' (participación en elecciones y lucha armada; infiltraciones, retenciones, ajusticiamientos), con lo cual se ha agravado la crisis sin llegar a ninguna solución”.

En resumen, con relación a esta pregunta específica, si el estudiante igualó el punto de vista del autor con el punto de vista de la guerrilla es porque no entendió la paráfrasis y/o porque probablemente no leyó el pie de página número (iii), lo cual significa ignorar las marcas del texto y no leer desde la perspectiva de su organización.

Frente al estudiante que seleccionó la opción (D), consideramos que se concentró en la primera parte del párrafo 1.3. En él, la izquierda democrática admite, por un lado, que sí existe un conflicto social y político; y por otro, reconoce la existencia de la injusticia social, la corrupción y la mala distribución de la riqueza, mencionados en el párrafo 1.2, a propósito del punto de vista de los alzados en armas. Sin embargo, este estudiante pasó por alto la posición de la izquierda democrática, según la cual dichos problemas "no se pueden resolver con la lucha armada ni con la confrontación militar", como se expresa en el texto. Posición que se reafirma en dos lugares más: en el pie de página número (iv), cuando habla sobre "el reconocimiento de la existencia en Colombia de un conflicto armado interno de carácter social y político cuya solución debe ser política, mediante acuerdos encaminados tanto a terminar la guerra como a atacar las raíces del conflicto". Esta posición se ratifica también en la paráfrasis del autor al punto de vista de la izquierda democrática: "Sólo mediante negociaciones entre ellos, consensos y pactos con objetivos definidos, es posible encontrar salidas viables al laberinto en que nos encontramos".

Finalmente, todos los estudiantes que se equivocaron al descartar la opción correcta (E), pudieron haberse basado en el hecho de que Caballero no manifiesta explícitamente estar en contra de la extradición de los cabecillas de la guerrilla y de los grupos paramilitares. Como ya se ha señalado, la posición de este columnista con respecto a este tema debe ser inferida por el lector a partir de un fragmento ya citado, en el que Caballero señala la inconveniencia de la extradición para una salida negociada del conflicto.

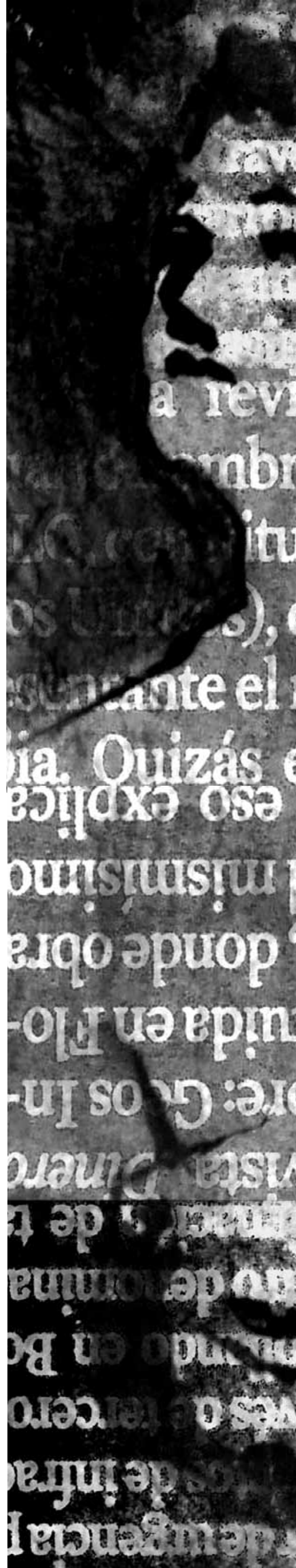




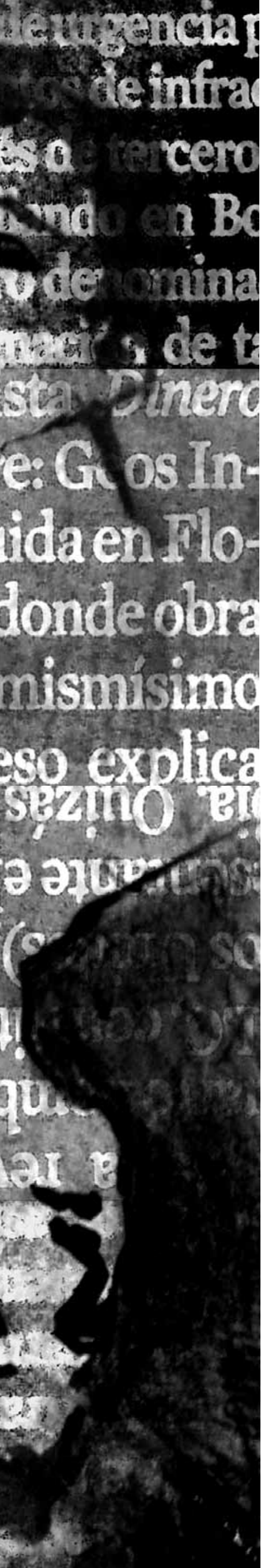

\section{CONCLUSIONES}

Los análisis propiciados por esta investigación nos permitieron profundizar en los distintos niveles del proceso de comprensión textual:

- La enunciación en el texto escrito, diferenciando el enunciador dominante y los enunciadores referidos con sus respectivos enunciados.

- La producción de inferencias por parte del lector.

- El uso de conocimientos semánticos para la producción de inferencias y para la comprensión en general

- El uso de conocimientos procedimentales propios de la cultura escrita.

- El reconocimiento de las macroestructuras, que implica relacionar las distintas partes del texto.

- La identificación de las superestructuras expositivo-argumentativas.

- La relación entre los conocimientos previos (semánticos y procedimentales) y los conocimientos nuevos aportados por un escrito.

- La lectura desde la perspectiva de la organización del texto y no sólo desde la perspectiva del lector y su cognición social.

Como pude verse a lo largo de éste y otros artículos igualmente publicados, no nos hemos limitado a la cuantificación de los aciertos y los errores de los estudiantes examinados. Lo que también nos interesa indagar son las posibles explicaciones tanto de los errores como de los aciertos, con base en el modelo teórico que hemos propuesto desde la lingüística textual y la teoría de la enunciación como dos enfoques complementarios. Es desde ellos, mediante un proceso de argumentación lógica, que hemos podido vislumbrar las operaciones y los procedimientos implicados, las presuposiciones puestas en acción y las inferencias hechas o por hacer al momento de responder el cuestionario.

Ateniéndonos a los resultados cuantitativos, podemos decir que sólo tres de los veinte estudiantes evaluados (el 15\% de ellos) están en condiciones ideales pues respondieron acertadamente todo el cuestionario, lo cual indica su buen nivel de conocimientos procedimentales y su alto grado de adscripción a la cultura escrita, por lo menos en lo que concierne a la lectura.

En segundo lugar, los doce estudiantes que acertaron en cuatro de las cinco preguntas (el 60\% de la muestra) aún carecen de ciertos conocimientos procedimentales, no leen plenamente desde la perspectiva de la organización del texto (no relacionan las partes que lo componen) y les falta consolidar su capacidad para inferir. Como bien sabemos, estos tres aspectos son interdependientes y están íntimamente relacionados.

Los cinco estudiantes que se equivocaron en dos o más preguntas (el 25\% de quienes presentaron la prueba de lectura) se encuentran distantes del modelo de lectura de los textos expositivosargumentativos, requerido para la apropiación de conocimientos en el ámbito universitario.

Finalmente, consideramos que este análisis no puede presentarse de manera aislada. Los resultados obtenidos en las pruebas aplicadas, la información aportada por los estudiantes en la entrevista, la observación de textos académicos y no académicos proporcionados por ellos y el análisis de su trayectoria escolar, permitirán conocer en detalle el grado de adscripción de los sujetos de la investigación a la cultura escrita y su grado de pertenencia a la tecnocultura contemporánea, así como identificar posibles relaciones de tensión o de complementariedad entre ambas. Finalmente, la información obtenida nos permitirá establecer posibles correlaciones entre el grado de adscripción de los estudiantes a la cultura escrita y a la tecnocultura, y su rendimiento académico en la universidad, considerado este último como una de las manifestaciones de su nivel de apropiación de conocimientos especializados. 
1. Para conocer el marco conceptual de las dos investigaciones sobre cultura escrita, tecnocultura y conocimiento en la universidad, ver Ulloa y Carvajal 2006, 2008a, 2008b, 2009.

2. La cultura escrita abarca conocimientos semánticos y conocimientos procedimentales específicos. Mientras los conocimientos semánticos aluden a un "saber qué", es decir, a saberes declarativos, los conocimientos procedimentales se refieren a un "saber cómo", un saber hacer. En el caso particular de la lectura y la escritura, los conocimientos procedimentales constituyen un "saber hacer" textos coherentes o un "saber hacer" para lograr la comprensión cuando se lee. Por ejemplo, no se trata sólo de saber qué son los marcadores deícticos (lo cual correspondería a un conocimiento semántico), sino de saber emplearlos adecuadamente en la construcción de un enunciado coherente o poder reconocer su significación en un determinado contexto cuando se trata de comprender un escrito.

3. Como se ha expuesto en el marco teórico de esta investigación, diferenciamos los conocimientos previos de carácter procedimental, de los conocimientos previos de carácter semántico. En la mayoría de los estudios al respecto, no se hace esta distinción... Así por ejemplo, identificar al enunciador dominante y reconocer los distintos enunciadores con sus respectivos enunciados y puntos de vista, presentes o implícitos, es un conocimiento procedimental, indispensable para la comprensión y por lo tanto para la apropiación de nuevos conocimientos semánticos.

4. La fuerza ilocutiva, o ilocutividad, alude a lo que se hace con lo que se dice. La fuerza ilocutiva determina cómo debe recibirse el enunciado por el receptor (si como pregunta, como queja, como afirmación, como amenaza, como promesa, como un favor o como una orden, etc.). Para ampliar este concepto, ver Austin (1962), Ducrot y Todorov (1981), Ducrot (1988).

\section{Bibliografía}

Austin, J. L. (1962). How to do things with Words. Cambridge: Oxford.

Bakhtin, Mikhail (Volochinov). (1997). Marxismo e Filosofía da Linguagem, Sao Paulo: Editora Hucitec.

Benveniste, Emile. (1977). El Aparato Formal de la Enunciación, en Problemas de Lingüística General II (pp. 82-91). México: Siglo XXI Editores.

Chomsky, Noam. (1974). Estructuras sintácticas. México: Editorial Siglo XXI.

De Torres, Julio Santiago, et al. (1999). Procesos Psicológicos Básicos. Madrid: Editorial Mc Graw Hill.

Ducrot, Oswald \& Todorov, Tzvetan. (1981). Diccionario Enciclopédico de las Ciencias del Lenguaje. México: Siglo XXI Ediciones.

Ducrot, Oswald. (1988). Polifonía y Argumentación, Conferencias del Seminario "Teoría de la argumentación y análisis del discurso”. Cali: Universidad del Valle.

Greimas, A.J. \& Courtés, J. (1982). Semiótica, Diccionario razonado de la teoría del lenguaje. Madrid: Editorial Gredos.

López, Gladys Stella. (1997). "Los esquemas como facilitadores de la comprensión y el aprendizaje de textos”. En Revista Lenguaje, No 25 (pp. 40- 55). Cali: Escuela de Ciencias del Lenguaje, Universidad del Valle.

Parodi, Giovanni \& Núñez, Paulina. (2002). Propuesta de intervención pedagógica para la comprensión e interpretación de textos académicos. Cali: Cátedra UNESCO para la lectura y la escritura en América Latina, Universidad del Valle.

Sánchez, Emilio, (1997). Los Textos Expositivos. Estrategias para mejorar su comprensión, Buenos Aires: Santillana.

Searle (1969). Speech Acts. A essay in the Philosophy of Languaje. Cambridge: Cupress. 
